\title{
EL PENSAMIENTO POLÍTICO DE MARIANO OTERO
}

José Fernández Santillán*

\section{La frase, por demás emotiva y tris-} te, "en México no hay ni ha podido haber eso que se llama espíritu nacional, porque no hay Nación" se encuentra en un documento titulado Consideraciones sobre la situación politica y social de la República Mexicana ${ }^{1}$ que vio la luz en diciembre de 1847. Dicho documento no tiene rúbrica personal, simplemente aparece como obra de "Varios mexicanos", pero los especialistas en la materia le atribuyen la esencia de su redacción, sin sombra de duda, a uno de los pilares del liberalismo mexicano del siglo XIX, el jalisciense Mariano Otero.

La fecha de publicación de las Consideraciones es significativa: en esos momentos nuestro país se hallaba invadido por tropas estadounidenses encabezadas por el General Winfield Scott. Tres meses antes, es decir en septiembre, había caído el último bastión que resguardaba la capital de la república. Como consecuencia de la derrota dos meses después de la aparición del escrito en cuestión, o sea en febrero de 1848, se firmó el Tratado de Guadalupe Hidalgo por medio de cual México perdía más de la mitad de su territorio. Vale la pena señalar al respecto que Mariano Otero fue uno de los cuatro diputados que se opusieron a la firma de esa capitulación.

* Departamento Académico de Ciencias Sociales, ITAM.

${ }^{1}$ Cfr. Mariano Otero, Obras, 1967, México, Porrúa, vol. I (recopilación, selección, comentarios y estudio preliminar de Jesús Reyes Heroles), p. 127. 
El ánimo que campeaba en aquellos días era de desolación, pero también de reflexión crítica acerca de las condiciones que provocaron la rendición frente al enemigo. En ese estudio Otero, después de una larga disquisición en torno a la composición terriblemente inequitativa de la sociedad y de la economía del país, y luego de elucubrar sobre las múltiples debilidades de la legislación y de las instituciones, llegó descarnadamente a esa amarga conclusión: México había sido presa de las ambiciones expansionistas de los Estados Unidos, ante todo porque no constituía una unidad política; no era un Estado bien armado que pudiera hacer frente a la dispersión interna y a la agresión externa. De manera concomitante en ese momento tampoco existía el sentimiento nacionalista. Ese sentimiento se fue abriendo paso, paulatinamente, a raíz del descalabro frente al embate de los Estados Unidos y, posteriormente, con la lucha que México tuvo que librar contra la intervención francesa en la década de los sesenta del siglo XIX. El nacionalismo mexicano terminó de consolidarse sólo en el presente siglo con la Revolución de 1910.

Lo que había en la época de Otero era un pueblo en estado de disolución merced a los conflictos entre facciones opuestas: "Divididas

14 las clases - sigue diciendo Otero en su análisis - en bandos con tales o cuales principios políticos, cada uno de esos partidos cree o pretende que sus contrarios son la única causa de las desgracias de la nación; y es tal y tan ciego el frenesí con que sostienen sus diversas opiniones, que verían sin duda con menos sentimiento la pérdida total del país, que el triunfo de cualquier partido que no fuese el suyo."2

A nuestro parecer, es dudoso que alguien se sintiese satisfecho al ver, o saber, que la bandera de las barras y las estrellas ondeaba en Palacio Nacional; lo probable es, en cambio, que muchos, sobre todo los dirigentes de las distintas corrientes, hubiesen reflexionado sobre su proceder y la responsabilidad que les tocaba asumir al haber convertido al lugar donde nacieron en campo de batalla.

${ }^{2}$ Ibid., p. 129. 
Habían sido numerosos los levantamientos, rebeliones y traiciones durante los años previos a la invasión norteamericana, de manera que en medio de la constante incertidumbre había sido imposible erigir un orden gubernamental que tuviese continuidad en su funcionamiento. México fue derrotado no tanto por la superioridad bélica de su vecino del norte, sino por la carencia de vínculos entre sus hombres. Para Otero el egoísmo miope que predominó en buena parte del período posterior a la consumación de la independencia imposibilitó el florecimiento del sentimiento patriótico; no había, propiamente dicho, una identidad colectiva que moviera a los mexicanos por encima de sus preferencias individuales hacia el logro de un propósito común.

Quien fuera también diputado en el Congreso Constituyente de 1842, reconoció que la ausencia del sentimiento de pertenencia a un cuerpo político se debía a la falta de educación y moralidad en la población. En diversas ocasiones mostró su preocupación por la situación en la que se hallaba el pueblo llano, sumergido "en la más espantosa miseria, resultado preciso de la abyección y embrutecimiento en que se le mantenía. Acostumbrado a una vida holgazana y vagamunda, sus diversiones favoritas eran los toros, las procesiones religiosas, que eran casi diarias, las romerías, las novenas, y por último, los garitos y las tabernas, donde pasaba el tiempo entregado al juego y la embriaguez". 3 Vale decir, la gente se hallaba distraída cultivando los placeres mundanos o las devociones celestiales sin atender los problemas colectivos. En esas circunstancias era obvio que había debilidad en los intentos de aglutinación. Sólo eso explica que no pudiera detenerse el avance de las fuerzas invasoras: las tropas norteamericanas que penetraron en México no pasaban de catorce mil hombres, en tanto que la población de las regiones por las que incursionaron sumaba dos millones de personas.

A juicio del tapatío la Iglesia católica era un factor que pesaba en contra de los esfuerzos de integración: era propietaria de las tres cuartas partes del territorio nacional, tierra que en su mayor parte se mantenía

${ }^{3}$ Ibid., p. 131. 


\section{JOSÉ FERNÁNDEZ SANTILLÁN}

ociosa. Las corporaciones religiosas tenían el dominio de las conciencias, oponiéndose a los propósitos de la educación ilustrada, además los curas se inmiscuían constantemente en los asuntos civiles, sin reconocer otro poder que el de la jerarquía a la que pertenecían, lo cuallos llevaba a bloquear el desarrollo de las instituciones gubernamentales. Sobre el particular escribe: "Domina en esta sociedad un clero falto en lo general de instrucción y de virtudes, pero suficientemente astuto y avaro, que en trescientos años de fanatismo se había hecho dueño de la mayor parte de la propiedad raíz de la nación; un clero que, además de la influencia de que ya gozaba con la posesión de sus inmensas riquezas, tenía monopolizada la educación de la juventud en los colegios, en los púlpitos y en los confesionarios, donde infundía todas las ideas que eran conducentes a asegurar cada día más su poder... un clero, por último, que se creía con el derecho de influir y aun dirigir todos los negocios públicos, y que a su vez tenía la pretensión de no depender para nada del gobierno."4

Entre el momento en que Otero escribe, junto con otros compatriotas, las Consideraciones (1847) y el de la entrada de Agustín de Iturbide a la ciudad de México al frente del Ejército Trigarante (1821), pasaron veintiséis años. No obstante, la liberación del dominio español no había encontrado correspondencia con la formación de un cuerpo colectivo cuyas partes estuviesen armónicamente integradas. Sobre el particular afirma: "La obra de la independencia, es decir, el hecho de destruir por la fuerza el gobierno virreinal, era la parte más fácil de aquella atrevida empresa, porque no era más que un hecho de armas, para el cual no se necesitaba verdaderamente sino la audacia y el valor suficiente para combatir. Pero una vez consumado aquel hecho, quedaba por hacer la parte más dificil de la obra, esto es, la regeneración política de la sociedad, la cual no podía operarse sino organizando un gobierno." Si era verdad que la independencia había sido alcanzada, no era igualmente cierto que el mundo colonial hubiese desaparecido

\footnotetext{
${ }^{4}$ Ibid., p. 130-1.

${ }^{5}$ Ibid., p. 134.
} 
por completo; muchas eran las herencias de aquel pasado de opresión que todavía quedaban vivas; en tanto que el mundo republicano y liberal aún estaba en ciernes. Otero era un "hombre de dos mundos", al estar situado entre el pasado virreinal y el futuro secular, pero no por ser una combinación contradictoria entre las ideas de uno y otro momento. Muy por el contrario: él fue uno de los ideólogos más comprometidos con el progreso civilizatorio.

En sus escritos, aparte de la huella de autores como Voltaire o D'Alambert, también se registra la influencia de Montesquieu, Rousseau, Madame de Stäel, Constant y Sismondi, además de la de Tocqueville. En contraste con diversos pensadores y políticos mexicanos de su tiempo, todavía permeados por el pensamiento eclesiástico o por escritores premodernos, Otero pertenece por entero al bando de quienes se identifican con los ideales de la modernidad. Esto es, con su reivindicación de los derechos del hombre, el aprecio por la superioridad de la norma jurídica y la convicción de que para salir del atraso y el oscurantismo hay que constituir un Estado fuerte, mas no autoritario.

Se ha dicho que debido a esta profunda identificación con los valores de la modernidad Otero elaboró una verdadera y propia filosofía de la historia: Contempló el devenir como progreso, o sea, como conquista paulatina de niveles superiores de evolución teniendo como guía a la razón. Pero esta visión progresiva de la historia no quería decir determinismo inamovible bajo el cual los acontecimientos seguían indefectiblemente una ruta trazada de antemano. Su perspectiva no es unilineal: reconoce las interacciones, movimientos y mutaciones que intervienen en los procesos sociales; no hay predicción que valga para anticipar el resultado de esa dinámica; nada está predeterminado. El programa de la modernidad podía cumplirse o no.

Desde esta óptica analiza al país y a su tiempo - su obra literaria está concentrada básicamente entre 1842 y 1850 (año en el que muere víctima de la epidemia de cólera que azotó a la ciudad de México)y entiende que la alternativa política con la que se identifica deberá hacer frente a dificultades de enorme magnitud, comenzando por el hecho de que México se debatía en la anarquía. Había, pues, que le- 


\section{JOSÉ FERNÁNDEZ SANTILLÁN}

vantar al país de la postración en la que se encontraba mediante la consolidación del Estado nacional.

Toda proporción guardada, la observación que realiza Otero no está lejos, conceptualmente, de la que realizara Maquiavelo en $E l$ Príncipe a principios del siglo XVI sobre la situación catastrófica que afligía a Italia, desmembrada en una infinidad de pequeños reinos en lucha entre sí comandados por señores de horca y cuchillo que no veían más allá de su nariz. Italia, también se encontraba invadida por las potencias que en esos momentos se disputaban el dominio sobre Europa. A todo eso se añadía la presencia de la Iglesia católica la cual igualmente luchaba por mantener el dominio sobre un gran número de zonas y personas de la atribulada península.

La perspectiva de Otero tampoco es distante de la que Hegel asumiera en La constitución de Alemania a principios del siglo XIX, cuando admitió dolorosamente que su país no era un Estado debido a que también se encontraba fragmentado en múltiples señoríos con sus administraciones y sistemas jurídicos, con sus particulares sistemas fiscales y ejércitos privados. La belicosidad entre ellos hacía que proliferara la violencia al no haber un poder por encima de las partes que las obligara a mantener la paz. La barbarie, la miseria y el atraso eran consecuencia lógica de tan lamentable situación.

La solución que presenta Maquiavelo para superar la dispersión anárquica es el surgimiento de un líder, un Príncipe que pusiera en su lugar por medio de la fuerza a los señores de la guerra, aplicando el dicho "combatir al demonio con el fuego" y que expulsara del suelo patrio a los intrusos. El Secretario florentino, de igual manera pensaba que la Iglesia debía retrotraerse a su función primigenia que era la de encaminar las almas a la salvación y dejara de interferir en los asuntos terrenales ("dar al César lo que es del César y a Dios lo que es de Dios"). La consigna era, pues, edificar la monarquía concentrando el poder en las manos de ese Príncipe iluminado capaz de adoptar una perspectiva más amplia sobre el destino de Italia; para ello era preciso entender la lógica de la política que es, a fin de cuentas, la lógica del 


\section{EL PENSAMIENTO DE MARIANO OTERO}

poder en su dimensión más desprejuiciada, tal y como lo manifiesta en ese texto ya clásico del pensamiento político.

Sobre la horma de Maquiavelo, Hegel sostenía la conveniencia de restablecer la unidad de Alemania mediante la formación de un gobierno monárquico y constitucional que desempañara unitariamente las funciones administrativas, legislativas, fiscales y de defensa. Un Estado nacional que se precie de tal nombre no puede dejar en el aire asuntos tan relevantes so pena de retornar al feudalismo.

Otero, según lo han dicho sus biógrafos, no tuvo acceso a las obras de Hegel; en cambio es probable que conociese las ideas de Maquiavelo. De cualquier forma, el pensamiento de los autores que enunciamos más arriba, y que determinaron su orientación ideológica, está embuido del propósito fundamental de crear y mantener el poder para darle coherencia y rumbo a la nación. La unidad del Estado es un tema recurrente del pensamiento político moderno y Otero lo asumió con todo rigor. Le tocó un momento en que resultaba imperativo formar una Nación. Pero no creía que eso debía hacerse a la manera de Maquiavelo, a través del ejercicio de la violencia; su idea era, más bien, lograr un arreglo pacífico entre las distintas fuerzas inmiscuidas en la problemática. Ya desde 1842, en su Ensayo sobre el verdadero estado de la cuestión social y política que se agita en la república mexicana, lanzaba la voz de alerta sobre el peligro, que después se hizo realidad, de que por las contiendas internas se perdiera más de lo que ya se había perdido con Texas. En ese trabajo sostuvo, con ánimo conciliador, que "en las instituciones fundamentales no se debe preparar la lucha, sino el acuerdo y la armonía de los elementos sociales". 6 Su posición no era la de armar a un líder carismático para que aniquilara o sojuzgara a los recalcitrantes sino la de convocar a todos, sin excepción, al entendimiento. La tesis que sostuvo Otero a lo largo de su corta pero fecunda trayectoria política (murió cuando apenas tenía treinta y tres años de edad) fue la del acuerdo en lo fundamental. La

6 "Ensayo sobre el verdadero estado de la cuestión social y política que se agita en la república mexicana", 1 de junio de 1842 , ibid., p. 75 . 


\section{JOSÉ FERNÁNDEZ SANTILLÁN}

sustancia del planteamiento consistía en que, a pesar de las profundas diferencias existentes era posible arribar a una confluencia en asuntos elementales. Una vez definidos esos asuntos, éstos se convertirían en la base de un convenio que todos se comprometerían a respetar. Otero estaba seguro de que se podían compartir ciertos principios esenciales.

En el proyecto oteriano hay una sólida coherencia: íntimamente vinculado a la tesis del acuerdo en lo fundamental está su planteamiento de la operatividad de una república representativa en la que sería absurdo que imperara exclusivamente el principio de mayoría. Sostenía que así como en la elaboración del convenio básico deben participar todas las fuerzas sociales, las mismas también deberian tener cabida, en la figura de sus representantes, en los órganos de representación. Por tanto - y ésta es otra de sus aportaciones-el principio de mayoría sólo tiene validez en la democracia a condición de que se complemente con el reconocimiento de las minorías. Un eslabón más de esta cadena propositiva es su defensa del sistema electoral de representación proporcional: sostiene que la representación política sólo es buena en cuanto es imagen de la sociedad, es decir, en cuanto refleja fielmente la diversidad de la base social. Dicho de otra manera: la representa-

20 ción política es aceptable en cuanto no produce un efecto distorsionador que haga ver más grande o más pequeña de lo que es a alguna parte de los ciudadanos. La contribución de Otero sobre este tema no es menor: apoyándose en Sismondi y Considérant se adelantó a teóricos de la proporcionalidad en las elecciones tan renombrados como John Stuart Mill o Hans Kelsen. Conviene recordar que su sugerencia no permaneció en la pura especulación filosófica, por el contrario, quedó plasmada en el proyecto de Constitución de 1842 .

Como se aprecia, las ideas de Otero eran sorprendentemente avanzadas para su tiempo: a mediados del siglo XIX ya convocaba a un acuerdo en lo fundamental, pedía la representación de las minorías y era favorable al sistema de representación proporcional. Sobre todo los dos últimos son tópicos abordados con posterioridad en los países políticamente más avanzados, y en México hasta hace relativamente poco asumidos como materia central de discusión. 
Otero, quien fuera también secretario de relaciones exteriores durante el gobierno de José Joaquín de Herrera entre junio y noviembre de 1848, decía que los Congresos Constituyentes eran la expresión real de lo que filosóficamente se había diseñado en el contractualismo de cuño iusnaturalista; también decía que las Constituciones emanadas de esas magnas asambleas eran la manifestación formal de la voluntad colectiva. Por ello estimaba que el acuerdo fundador de la República mexicana, esto es, el verdadero proyecto de México, se encontraba en la constitución federal de 1824. Sin embargo, esa constitución fue sustituida por las disposiciones centralistas de 1836 por medio de "las Siete Leyes". A su juicio, había que retomar el rumbo original, si bien con ciertas correcciones. Así y todo, más allá de los ajustes formales, lo importante era que la esencia del Congreso constituyente de 1824 no había perdido un ápice de validez: la subordinación del poder a la ley para que se pudiese hablar de un verdadero y propio Estado de derecho; la división de poderes (siempre desconfió de la fuerza que podía acumular el Ejecutivo y previó las consecuencias autoritarias que generaría ese hecho al romperse el equilibrio entre los órganos del Estado); el control sobre los gobernantes; las bondades del sistema federal. Había que refrendar aquel pacto de 1824 y ponerlo al día. Ése fue su propósito al participar en el Congreso constituyente de 1842. Congreso por cierto convocado a raíz del pronunciamiento conocido como Plan de Jalisco, capitaneado por Mariano Paredes Arrillaga el 8 de agosto de 1841. Plan que luego fue secundado por otros pronunciamientos, el de la Ciudadela el 4 de septiembre, y el de Perote el 9 de ese mismo mes. Todos esos pronunciamientos fueron a parar en las Bases de Tacubaya del 28 de septiembre de ese año y condujeron a la caída de Anastasio Bustamante. Como consecuencia Antonio López de Santa Anna quedó facultado para lanzar la Convocatoria del nuevo Congreso constituyente. La mención de esta secuela de acontecimientos es relevante porque a raíz del Plan de Jalisco Otero tuvo la oportunidad de aparecer en la vida política de su región y luego en la política nacional. 


\section{JOSÉ FERNÁNDEZ SANTILLÁN}

Lo que precisamente marca su entrada a la política nacional es el célebre Discurso que pronunció el 11 de octubre de 1842 en dicha asamblea constituyente. En su disertación hizo una apasionada defensa de la forma de gobierno republicana y, en especial, del sistema federal. En contra de lo que sostenían los simpatizantes del centralismo en el sentido de que el federalismo en nuestro país no era más que una burda copia del estadounidense, Otero refuta tal aseveración señalando que nunca se ha visto en alguna parte del mundo la reproducción idéntica de un determinado régimen. Cada país tiene sus peculiaridades $\mathrm{y}$, en consecuencia, cada aplicación tiene su propia originalidad. Además recuerda que, hablando rigurosamente, los norteamericanos no inventaron el sistema federal, dado que en el mundo antiguo ese sistema ya había sido adoptado por los griegos. Con posterioridad también lo aplicaron muchos otros, como los suizos, los alemanes y los holandeses. De igual forma rechaza la idea de que el federalismo terminaría de desmembrar a la Nación: para él el federalismo no sería causa de dispersión; al contrario, sería motivo de integración porque permitiría que las partes se fortalecieran para, al mismo tiempo, robustecer al conjunto nacional. Esgrimiendo estas razones, concluye que los detractores del federalismo no combaten tanto a ese esquema en particular, sino que va de por medio su propósito de combatir al sistema republicano. En efecto, algunas de las facciones más conservadoras aún pretendían instaurar el régimen monárquico, el cual es rechazado frontalmente por Otero en cuanto sería un retroceso porque esa forma de gobierno considera a los individuos no como ciudadanos con derecho de participación, sino como súbditos con la obligación exclusiva de obedecer. Además Otero advierte que la monarquía sí sería una adaptación extralógica dado que requiere de la existencia de la aristocracia como sucedió en Europa; pero resulta que esa clase en México, propiamente dicho, no existe.

Para reforzar su apología del federalismo Otero echa mano de Montesquieu, y lo cita: El autor de El espíritu de las leyes había dicho que tanto los estados grandes como los pequeños tenían inconvenientes. Los primeros porque sucumbían ante los vicios interiores, los segundos 
porque eran fácil presa de las fuerzas extranjeras. Ambos asuntos afectan por igual a las democracias y a las aristocracias, de manera que si no hubiese existido una salida al dilema se hubiera tenido que recurrir a la monarquía. Montesquieu encontró una puerta de escape al mismo: "es de presumir que los hombres se hubieran visto al fin obligados a vivir siempre bajo el gobierno de uno solo, si no hubieran imaginado una constitución que a todas las ventajas interiores del gobierno republicano reunía la fuerza exterior de las monarquías. Hablo de la república federativa". ${ }^{7}$ Ése era el fruto que bien podía aclimatarse en nuestro país. El secreto de su germinación estaba en establecer debidamente las funciones que a cada instancia correspondían, o sea, al poder federal unas, y a las entidades otras, de manera que no hubiese controversia entre lo que era responsabilidad de un nivel y de otro.

Es evidente que el restablecimiento del federalismo no caminaría por sí mismo; tendría que correr de la mano con la instauración del buen gobierno. Por buen gobierno entendía un régimen que contara con el respaldo de los ciudadanos y que por ello pudiese ser más estable y duradero. Otros elementos que concurrían a lograr esa cualidad en el ejercicio del poder eran el apego a las leyes y la orientación a responder a las necesidades de todos los componentes sociales y no sólo de una porción.

Esas apreciaciones que Otero pese a todo hacía aún con esperanza en su Discurso de 1842, (cuando escribió las Consideraciones) cinco años después se transformaron en decepción: "En los veinte y seis años que han transcurrido desde que se hizo la independencia, se han ensayado todas las formas de gobierno; pero como esos ensayos no han sido realmente sino de palabras, jamás se han emprendido las grandes reformas que reclama la civilización de la época en que vivimos, el país ha sido precipitado día a día a su destrucción y aniquilamiento,

${ }^{7}$ Este fragmento de Montesquieu es citado por Otero en el mencionado Discurso del 11 de octubre de 1842. Tomo la referencia de ibid., p. 303. En la obra de Montesquieu traducida al español este paso se encuentra en: $\mathrm{Del}$ espiritu de las leyes, 1977, México, Porrúa, libro IX, cap. I, p. 86. 
por la acción combinada de los vicios sociales que quedaron del sistema colonial, y los que se han aumentado en 26 años de desórdenes." 8

Sea como fuere, decepciones aparte, Otero no se quedaba en su propuesta de cambio y mejoramiento en lo que podríamos llamar la parte institucional y formal. Iba más allá al considerar que el establecimiento de un buen gobierno era un elemento de primer orden para sacar adelante al problema social. Su planteamiento acerca de la transformación social se sintetiza en dos rubros: 1) el cambio de la sociedad debe venir de las modificaciones de las relaciones materiales, esto es, de las relaciones económicas; 2) estabilidad no significa parálisis de la sociedad, muy por el contrario quiere decir aprovechar las contradicciones entre las clases y los sectores que las constituyen canalizando esa energía para impulsar el progreso. En este sentido Otero pedía la superación del conflicto destructivo, pero a la vez solicitaba el mantenimiento e incluso el incremento del antagonismo constructivo porque sólo con base en este último la sociedad progresa; se trata de una conflictividad acotada. Hacia ese aspecto apunta la ley de la perfectibilidad social.

Al ocuparse de la sociedad y de la economía Otero solía atender 24 especialmente el tema de la propiedad. A la manera del inglés James Harrington, establecía un vínculo estrecho entre la forma de propiedad y el régimen político: de la manera en que esté repartida o concentrada la propiedad depende en buena medida el tipo de forma de gobierno que se establezca. Una alta concentración de los bienes producía generalmente gobiernos autoritarios, en tanto que una mejor distribución de la riqueza sería la base de las repúblicas democráticas. Siendo partidario de esta constitución, Otero pensaba en una sociedad de propietarios y no de terratenientes.

Es curioso y no carente de significado el hecho de que en sus primeros escritos hablara de la diferencia entre propietarios y no propietarios, y que en los últimos se refiriera más bien a la distinción entre clases productivas y no productivas. Interpretando este cambio po-

${ }^{8}$ Mariano Otero, op. cit., p. 65-6. 
dríamos decir que no bastaba con que la tierra estuviera repartida de forma más equitativa, sino que también fuese trabajada y no quedase, como hasta entonces, en manos de propietarios improductivos, por bien distribuida que ahora estuviese.

Una mejor distribución y una mayor productividad social generarían una mejor calidad de hombres, aptos para asumir de mejor talante la calidad de ciudadanos. Conceptualizaba la calidad de ciudadano como la capacidad de hacer buen uso de la libertad civil en cuanto individuos particulares a la manera del pensamiento liberal; pero ciudadano para él significaba, al mismo tiempo, capacidad de ejercer la libertad política en cuanto participación en la definición de los asuntos colectivos, a la manera del pensamiento democrático. Era así como Otero combinaba el liberalismo con la democracia.

Es para tomarse en cuenta, por añadidura, que en la gran mayoría de sus estudios abordó el análisis de las clases sociales y la manera en que ellas están organizadas en términos económicos. Este análisis siempre lo interrelacionó con los aspectos jurídicos y políticos en pos de un mejoramiento del poder público. Relacionando férreamente ambas cosas afirmaba insistentemente: "dos son los grandes bienes a que debemos aspirar. El progreso de nuestros elementos sociales y la conservación de la unidad nacional".?

Algo que se le debe reconocer a Otero es que en medio de la amargura y la decepción al ver a su país invadido, y a la vez hundido en desgarramientos internos, extrajo lecciones provechosas. Juzgó que la intervención norteamericana había sido "un desengaño saludable" porque ciertamente habíamos sufrido una dolorosa mutilación territorial, pero que sobre la parte que nos quedaba teníamos pleno dominio, por lo que podíamos rehacernos. La causa de México era una causa justa que animaba a continuar en la formación de la Nación.

Asumió el trabajo intelectual como una aventura orientada no a la elucubración teórica sino a la aplicación concreta. Su lema favorito era conocer para transformar, y así obró en consecuencia. Su proyecto

$$
{ }^{9} \text { Ibid., p. 67-8. }
$$


JOSÉ FERNÁNDEZ SANTILLÁN

se puede sustanciar en la siguiente frase: "El establecimiento de un orden social equitativo y justo, en el que la libertad sustituya un día completamente a la servidumbre, la igualdad a los privilegios, y la voluntad nacional a la fuerza bruta." 10

Tiene razón Jesús Reyes Heroles cuando afirma que el cúmulo de ideas que estaba en la cabeza de Otero "quedó como un rico legado para México"."11

${ }^{10}$ Ibid., p. 58 .

${ }^{11}$ Ibid., p. 173. 